\title{
Host size influences prevalence and severity of Kudoa thyrsites (Cnidaria: Myxosporea) infection in Atlantic salmon Salmo salar
}

\author{
Simon R. M. Jones* , Amy Long \\ Pacific Biological Station, 3190 Hammond Bay Road, Nanaimo, British Columbia, V9T 6N7, Canada
}

\begin{abstract}
Kudoa thyrsites is a cosmopolitan myxozoan parasite of marine fish. The infection causes an economically important myoliquefaction in farmed Atlantic salmon in British Columbia, Canada. Laboratory exposure of Atlantic salmon smolts to infectious seawater was used to test the hypothesis that infection with $K$. thyrsites is more severe in age-matched, smaller salmon. In each of 2 trials approximately 4 mo apart, smolts were graded into small (80 and $68 \mathrm{~g}$ ), medium (117 and $100 \mathrm{~g}$ ) and large (142 and $157 \mathrm{~g}$ ) initial weight groups (IWGs) and concurrently exposed to infectious seawater. The effects of IWG and time on fish size and infection severity were assessed by linear mixed-effects models. The fish were screened for infection by histological examination at intervals following exposure. Increases in mean length and weight were statistically significant in all IWG during both trials. The infection was detected in fish in both trials, and in Trial 2, the prevalence was significantly greater in larger fish 1000 degree-days (DD) after exposure. The severity of infection (plasmodia $\mathrm{mm}^{-2}$ muscle) was significantly higher in larger smolts: between medium and large IWGs at 2500 DD in Trial 1 and between small and medium IWGs at 1500 and 2000 DD in Trial 2. The hypothesis is rejected and possible explanations for the greater occurrence of $K$. thyrsites in larger smolts are discussed.
\end{abstract}

KEY WORDS: Kudoa thyrsites $\cdot$ Myxozoa $\cdot$ Atlantic salmon $\cdot$ Salmo salar $\cdot$ Size $\cdot$ Muscle $\cdot$ Infection

\section{INTRODUCTION}

Kudoa thrysites is a myxozoan parasite of the muscle of marine fishes. In the Pacific waters of North America, the Pacific hake Merluccius productus is an important host although $K$. thyrsites has also been reported from numerous other fish species (Kabata \& Whitaker 1981, Kabata \& Whitaker 1989, Moran et al. 1999a, King et al. 2012). In most hosts, parasitic plasmodia containing the characteristic stellate myxospores develop within myocytes of the striated muscle, although in Pacific salmon Oncorhynchus spp. and infrequently in Atlantic salmon Salmo salar, the parasite also occurs within cardiac myocytes (Kabata

\footnotetext{
*Corresponding author: simon.jones@dfo-mpo.gc.ca
}

et al. 1986, Kabata \& Whitaker 1989, Moran et al. 1999b). Harrell \& Scott (1985) first reported K. thyrsites in seawater netpen-reared Atlantic salmon in Puget Sound, Washington, USA, and the infections have since been well documented in cultured Atlantic salmon in British Columbia (BC), Canada (St Hilaire et al. 1997, Marshall et al. 2016). Fish are exposed to the parasite in infectious seawater that is assumed to contain the infective stage, likely an actinospore. Plasmodia require several weeks to months to develop. Despite the ubiquitous distribution and broad host range of the parasite, the life cycle has not been elucidated and an invertebrate host has not been described.

() Fisheries and Oceans Canada 2019. Open Access under Creative Commons by Attribution Licence. Use, distribution and reproduction are unrestricted. Authors and original publication must be credited. Publisher: Inter-Research - www.int-res.com 
In Atlantic salmon, post-mortem myoliquefaction at the site of $K$. thyrsites infection reduces fillet quality, with a significant cost to industry (Funk et al. 2008, Lafferty et al. 2015, Jones et al. 2016). The severity of tissue degradation is proportional to the parasite burden in the muscle (Dawson-Coates et al. 2003, Funk et al. 2007) and is caused in part by proteolytic enzymes, including a cathepsin $\mathrm{L}$ that is secreted by the plasmodium (Funk et al. 2008).

Although clinical signs are not associated with the infection, there are host-specific patterns of parasite development and host response. In Pacific hake, there is no evidence of a host response prior to complete occupation of the myocyte by the parasite (Stehr \& Whitaker 1986). During co-infections with $K$. thyrsites and $K$. paniformis, affected muscle cells become encapsulated and eventually heavily pigmented, and this process occurs more frequently in older fish (Morado \& Sparks 1986). In Atlantic salmon, the infection is self-limiting (Moran \& Kent 1999, Moran et al. 1999b, Jones et al. 2016) and recovered fish are refractory to reinfection (Jones et al. 2016). Infiltration of infected myocytes with inflammatory cells was initially believed to coincide with plasmodium maturation and rupture, a process that resulted in destruction of the myocyte (Moran et al. 1999b). Cells within this inflammatory lesion are known to phagocytise myxospores (Moran et al. 1999b). More recent observations indicate that cellular infiltration occurs shortly after infection of the myocyte (Braden et al. 2018), indicating that host recognition of the infection occurs at an early stage. Cells in this early infiltrate stage bear markers consistent with antigen-presenting macrophages, dendritic cells and/or cytotoxic T-cells. Together, these data are consistent with a protective immune response to $K$. thyrsites in Atlantic salmon, the initiation of which occurs during early parasite development within the myocyte.

The development of severe $K$. thyrsites infections in Atlantic salmon cultured in BC is mitigated by the practice of indirect entry: temporary rearing of smolts at production sites with a low $K$. thyrsites exposure risk, prior to grow-out at high-risk sites. While it is possible that prior exposure to the parasite at lowrisk sites elicits an acquired immune response, an alternative hypothesis is that the lower susceptibility of salmon upon transfer to the high-risk site is related to the increased size of the salmon at that time. The present study tests the hypothesis that risk of infection with $K$. thyrsites is increased in smaller postsmolt Atlantic salmon.

\section{MATERIALS AND METHODS}

\subsection{Exposure to Kudoa thyrsites and sample collection}

Two experimental trials were conducted at the Pacific Biological Station located at Departure Bay, Nanaimo, BC, Canada. Both trials involved exposure to raw seawater from Departure Bay, which leads to infection with $K$. thyrsites in naïve Atlantic salmon (Moran et al. 1999b, Jones et al. 2012, 2016). Naïve Atlantic salmon smolts were obtained in the autumn of 2015 (Trial 1) and the spring of 2016 (Trial 2) from 2 commercial hatcheries on Vancouver Island. Those obtained in 2015 were graded into initial weight groups (IWGs) of approximately 80, 117 and $142 \mathrm{~g}$, while those obtained in the spring of 2016 were graded into IWGs of approximately 68, 100 and $157 \mathrm{~g}$. The trials were designed to test the effect of host size on susceptibility to $K$. thyrsites, and in Trials 1 and 2, 200 fish in each IWG were assigned to each of two $2500 \mathrm{l}$ tanks and acclimated to ultraviolet-irradiated seawater (UVSW) over periods of 63 and $32 \mathrm{~d}$, respectively. Fish were fed a pelleted ration (Ewos Canada) at a daily rate of $1 \%$ of tank biomass. Exposure to the parasite was facilitated by replacement of UVSW with raw seawater supplied to the experimental tanks as reported earlier (Jones et al. 2016). In Trial 1, UVSW was replaced between 4 January and 27 February 2016, for an exposure of 512 degree-days (DD). In Trial 2, UVSW was replaced between 9 May and 23 June 2016, for an exposure of 522 DD. In both trials, the flow of UVSW was resumed thereafter and onset of exposure and accumulation of DD coincided with the first day of UVSW replacement. See Jones et al. (2016) for complete details of fish husbandry, exposure and sampling, which followed guidelines of the Canadian Council of Animal Care (Pacific Region Animal Care Committee AUP 15-009).

In Trials 1 and 2, samples were collected at 1093 and 1038 DD, 1588 and 1557 DD, 2097 and 1983 DD, and 2617 and 2583 DD, respectively. For clarity, these sampling times are herein identified as 1000, 1500, 2000 and 2500 DD. Immediately prior to sampling, the fish were sedated by adding $25 \mathrm{mg} \mathrm{l}^{-1}$ Aquacalm (Syndel Laboratories, Canada) to the tank water, then killed in seawater containing $250 \mathrm{mg} \mathrm{l}^{-1}$ MS-222 (Syndel). Length and weight were measured for each fish. Three pieces of epaxial skeletal muscle were dissected from standardized locations anterior to, adjacent to and posterior to the dorsal fin and preserved in neutral buffered $10 \%$ formalin (NBF). In Trial 1, samples of cardiac muscle were also collected 
at 2000 and $2500 \mathrm{DD}$ and preserved in NBF. After 5 to $7 \mathrm{~d}$, the NBF was replaced with $70 \%$ isopropanol for sample storage at room temperature.

\subsection{Histology and assessment of infection}

In both trials, NBF-fixed muscle samples from up to 20 fish per tank were dehydrated in an alcohol gradient, clarified in xylene and infiltrated with paraffin wax for subsequent sectioning, staining with hematoxylin and eosin, and histological examination (see Jones et al. 2012). An infection severity index for each fish was calculated as the arithmetic mean number of $K$. thyrsites plasmodia per $\mathrm{mm}^{2}$ from the 3 muscle sections. The median infection severity for each IWG was estimated from the severity indices of individual fish.

\subsection{Statistical analyses}

The significance of differences in the proportions of fish with detectable infections by IWG and time was determined using Chi-square tests. Statistical significance was assumed when $\mathrm{p}<0.05$. In each trial, the effects of IWG and time on length, weight and infection severity were analyzed with linear mixed-effects (LME) models using the nlme package in R version 3.4.3 (Pinheiro et al. 2017, R Core Team 2017). The fixed-effect terms were DD post exposure, IWG groupings and their interaction. The random effect was tank, and a term for unequal variance between treatments was included. For post hoc analyses, least-square means were generated in $\mathrm{R}$ using lsmeans from the package emmeans (Lenth 2018) with the lme model with the interac- tion term. Mean values were compared pairwise and adjusted p-values (Tukey) determined statistical significance.

\section{RESULTS}

From onset of exposure to final sampling, the durations of Trials 1 and 2 were 241 and 219 d, respectively. In Trial 1, the median (range) temperature during exposure to infectious seawater was $9.3^{\circ} \mathrm{C}$ $\left(9.1-10.2^{\circ} \mathrm{C}\right)$ and median salinity was $29.6 \mathrm{ppt}(28.9-$ $30.3 \mathrm{ppt})$. In Trial 2 , these values were $11.3^{\circ} \mathrm{C}(10.5-$ $\left.12.7^{\circ} \mathrm{C}\right)$ and $29.4 \mathrm{ppt}(28.2-29.8 \mathrm{ppt})$, respectively. The differences in median temperature $(p<0.001$, Mann-Whitney) and salinity ( $\mathrm{p}=0.044$, Mann-Whitney) between the 2 exposures were statistically significant.

\subsection{Fish growth}

Length and weight of experimental salmon increased in all IWGs over the course of both trials (Table 1). Length and weight were significantly influenced by the main effects (IWG, sample time) and in neither trial was the interaction between the two significant (see Tables S1 \& S2 in the Supplement at www.int-res.com/articles/suppl/d133p099_supp.pdf). In Trial 1, comparisons of length and weight among all IWGs were statistically significant (Tables S1 \& S2). Similarly, all comparisons among sample times but one (1500 versus 2000 DD) were significant. In Trial 2, all comparisons of length and weight among sample times were statistically significant $(\mathrm{p}<$ 0.0001 ), as were comparisons among IWGs ( $p<$ 0.0001; Tables S4 \& S5 in the Supplement).

Table 1. Mean $( \pm \mathrm{SD})$ length and weight of Atlantic salmon Salmo salar by initial weight group (small, medium or large) at intervals following exposure to Kudoa thyrsites infective seawater in Trials 1 and 2 (see Section 2.1 for details)

\begin{tabular}{|c|c|c|c|c|c|c|}
\hline \multirow{2}{*}{$\begin{array}{l}\text { Time } \\
\text { (degree-days) }\end{array}$} & \multicolumn{3}{|c|}{$\longrightarrow$ Fork length $(\mathrm{cm})$} & \multicolumn{3}{|c|}{ - Weight $(g)-$} \\
\hline & Small & Medium & Large & Small & Medium & Large \\
\hline \multicolumn{7}{|l|}{ Trial 1} \\
\hline 1000 & $26.8 \pm 4.5$ & $31.5 \pm 3.1$ & $31.5 \pm 2.6$ & $228.7 \pm 115.1$ & $349.8 \pm 90.9$ & $351.5 \pm 91.0$ \\
\hline 1500 & $28.7 \pm 3.8$ & $32.0 \pm 3.5$ & $33.0 \pm 3.9$ & $253.3 \pm 107.2$ & $355.1 \pm 125.4$ & $379.1 \pm 146.0$ \\
\hline 2000 & $30.1 \pm 3.7$ & $33.7 \pm 3.6$ & $35.0 \pm 3.8$ & $274.1 \pm 104.4$ & $396.7 \pm 150.0$ & $448.6 \pm 173.4$ \\
\hline 2500 & $33.2 \pm 3.1$ & $36.6 \pm 3.4$ & $37.4 \pm 3.1$ & $380.4 \pm 110.6$ & $539.5 \pm 155.0$ & $576.5 \pm 165.6$ \\
\hline \multicolumn{7}{|l|}{ Trial 2} \\
\hline 1000 & $26.0 \pm 1.7$ & $28.9 \pm 1.9$ & $30.1 \pm 2.3$ & $171.1 \pm 38.3$ & $237.0 \pm 47.8$ & $279.3 \pm 77.4$ \\
\hline 1500 & $28.0 \pm 2.1$ & $30.5 \pm 2.3$ & $32.2 \pm 2.5$ & $202.8 \pm 47.3$ & $275.9 \pm 65.2$ & $337.7 \pm 73.2$ \\
\hline 2000 & $30.4 \pm 1.6$ & $33.2 \pm 2.6$ & $35.4 \pm 2.8$ & $295.9 \pm 47.1$ & $387.4 \pm 81.2$ & $493.6 \pm 116.0$ \\
\hline 2500 & $34.3 \pm 2.4$ & $37.4 \pm 3.1$ & $40.8 \pm 2.8$ & $435.8 \pm 81.2$ & $560.4 \pm 128.8$ & $757.6 \pm 154.9$ \\
\hline
\end{tabular}




\subsection{Infection with Kudoa thyrsites}

In Trial 1, Kudoa thyrsites was undetected in salmon from the small and medium IWGs sampled at 1000 DD (Table 2). In all other IWG-DD combinations, the prevalence ranged from $4.2 \%$ in large IWG salmon at $1000 \mathrm{DD}$ to $42.5 \%$ in medium IWG salmon at 2500 DD. Differences in prevalence among sample times were statistically significant only in the medium IWG, and there were no statistically significant differences in prevalence among IWGs at any sample time (Table 2). Regarding infection severity (plasmodia $\mathrm{mm}^{-2}$ ), the interaction of IWG and sample time was statistically significant $(\mathrm{p}=0.032$; Table S3 in the Supplement). At $2500 \mathrm{DD}$, infection severity was significantly different $(p=0.003)$ between the medium and large IWGs (Table S3, Fig. 1). There was no evidence of the infection in heart muscle of 78 salmon collected from the large IWG at 2000 DD ( $\mathrm{n}=$ $39)$ and $2500 \mathrm{DD}(\mathrm{n}=39)$.

In Trial 2, the parasite was detected in all IWG-DD combinations. The prevalence ranged from $26.3 \%$ in salmon from the small IWG at 1000 DD to $100 \%$ in salmon from the large IWG at 1500 DD and the small IWG at 2000 DD (Table 2). Differences in prevalence among sample times were statistically significant in the small IWG, and among IWGs they were significant at $1000 \mathrm{DD}$. There was a statistically significant ( $p<0.029$ ) interaction between IWG and sample time (Table S6 in the Supplement). At both 1500 and

Table 2. Effect of size (see Section 2.1 for definition of initial weight group) and time post-exposure on prevalence of Kudoa thyrsites in skeletal muscle samples $($ Prev. $=$ number positive $/$ number examined $\times 100 \%$; by microscopic examination) from Atlantic salmon Salmo salar. Salmon in both trials were exposed to infectious seawater for approximately 520 degree-days (see Section 2.1)

\begin{tabular}{|c|c|c|c|c|c|c|c|}
\hline \multirow{3}{*}{$\begin{array}{l}\text { Time } \\
\text { (degree- } \\
\text { days) }\end{array}$} & \multicolumn{6}{|c|}{ Initial weight group } & \multirow{3}{*}{$\chi^{2}(p$-value $)$} \\
\hline & \multicolumn{2}{|c|}{ Small } & \multicolumn{2}{|c|}{ Medium } & \multicolumn{2}{|c|}{ Large } & \\
\hline & $\mathrm{n}$ & Prev. & $\mathrm{n}$ & Prev. & & Prev. & \\
\hline \multicolumn{8}{|l|}{ Trial 1} \\
\hline 1000 & 24 & 0.0 & 24 & 0.0 & 24 & 4.2 & $1.95(0.378)$ \\
\hline 1500 & 40 & 12.5 & 40 & 25.0 & 39 & 20.5 & $1.414(0.493)$ \\
\hline 2000 & 40 & 15.0 & 40 & 20.0 & 40 & 32.5 & $2.304(0.316)$ \\
\hline 2500 & 40 & 17.5 & 40 & 42.5 & 40 & 40.0 & $3.649(0.161)$ \\
\hline $\begin{array}{l}\chi^{2} \\
\text { (p-value) }\end{array}$ & \multicolumn{2}{|c|}{$\begin{array}{c}3.855 \\
(0.278)\end{array}$} & \multicolumn{2}{|c|}{$\begin{array}{c}9.917 \\
(0.019)\end{array}$} & \multicolumn{2}{|c|}{$\begin{array}{c}7.138 \\
(0.068)\end{array}$} & \\
\hline \multicolumn{8}{|l|}{ Trial 2} \\
\hline 1000 & 38 & 26.3 & 39 & 61.5 & 38 & 81.6 & $7.288(0.026)$ \\
\hline 1500 & 40 & 90.0 & 40 & 97.5 & 40 & 100.0 & $0.117(0.943)$ \\
\hline 2000 & 40 & 100.0 & 40 & 97.5 & 40 & 95.0 & $0.026(0.987)$ \\
\hline 2500 & 40 & 87.5 & 40 & 80.0 & 39 & 94.9 & $0.267(0.875)$ \\
\hline $\begin{array}{l}\chi^{2} \\
\text { (p-value) }\end{array}$ & \multicolumn{2}{|c|}{$\begin{array}{l}12.185 \\
(0.007)\end{array}$} & \multicolumn{2}{|c|}{$\begin{array}{c}2.370 \\
(0.499)\end{array}$} & \multicolumn{2}{|c|}{$\begin{array}{c}0.415 \\
(0.937)\end{array}$} & \\
\hline
\end{tabular}

$2000 \mathrm{DD}$, the difference in infection severity between the small and medium IWGs was significantly different (Table S6, Fig. 2).

\section{DISCUSSION}

In this study, we showed that naïve Atlantic salmon acquired infections with Kudoa thyrsites following relatively brief exposures to raw seawater from Departure Bay, BC, Canada, confirming our earlier observations (Jones et al. 2012, 2016). The effect of host size on the outcome of the K. thyrsites infection was examined under controlled laboratory conditions. Furthermore, LME models of host length and weight in the age-matched salmon confirmed that the IWGs were distinct size categories and maintained throughout the study, suggesting that on average, fish in the different IWGs differed in growth rates. This is not the first study to examine the effect of host size on the outcome of exposure to K. thyrsites infectious seawater. Over an 8-mo period, Jones et al. (2016) found evidence for increased risk of $K$. thyrsites in smaller salmon smolts within a population that had been serially exposed over time. As acknowledged in the earlier study, however, this apparent size effect was confounded by an uncontrolled seasonal effect in which the smaller fish were exposed during summer months. Of the 2 trials reported here, seawater during the late spring exposure (Trial 2) was warmer but less saline than that in the early winter (Trial 1). Previously, infections at this location were acquired by naïve Atlantic salmon during summer and autumn exposures but not during those in winter and early spring (Moran \& Kent 1999). Similarly, the abundance of $K$. thyrsites DNA is higher in seawater samples collected in late summer to autumn compared to those collected in winter (Jones et al. 2016), suggesting an increased infection pressure in late summer and autumn. In addition, because the salmon used in each trial were derived from different salmon production companies, genetic influences on the unequal magnitudes of infection observed in the trials should not be ruled out. The key finding from the present study was that despite the seasonal differences 


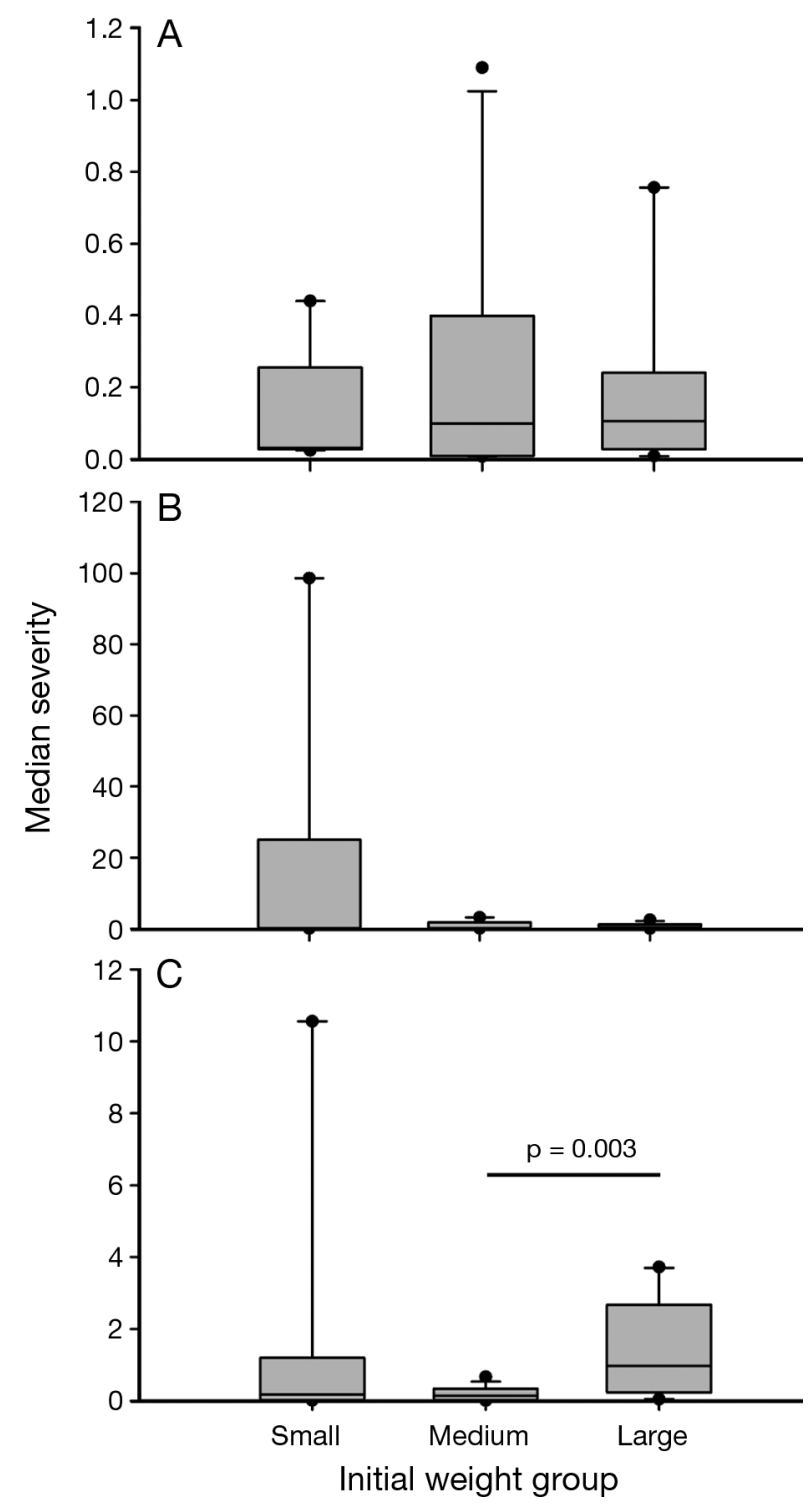

Fig. 1. Trial 1: Initial weight group (IWG)-associated median severity (plasmodia $\mathrm{mm}^{-2}$ ) of Kudoa thyrsites in Atlantic salmon Salmo salar skeletal muscle at (A) 1500, (B) 2000 and (C) 2500 degree-days following exposure to infectious seawater (note $y$-axis scales differ among plots; see Section 2.1 for IWG definitions). Boxes: median and 25th/75th percentiles; whiskers: 10th/90th percentiles; dots: 5 th/95th percentiles. Significant differences between treatments at a given sampling time are denoted by $\mathrm{p}$-values

between trials and possible genetic effects, similar patterns were observed such that infections in larger salmon had a shorter prepatent period and tended to be more prevalent and more severe than in the smaller fish.

The current data indicate that exposure of larger salmon resulted in infections with a more rapid onset and greater severity than concurrent exposure of
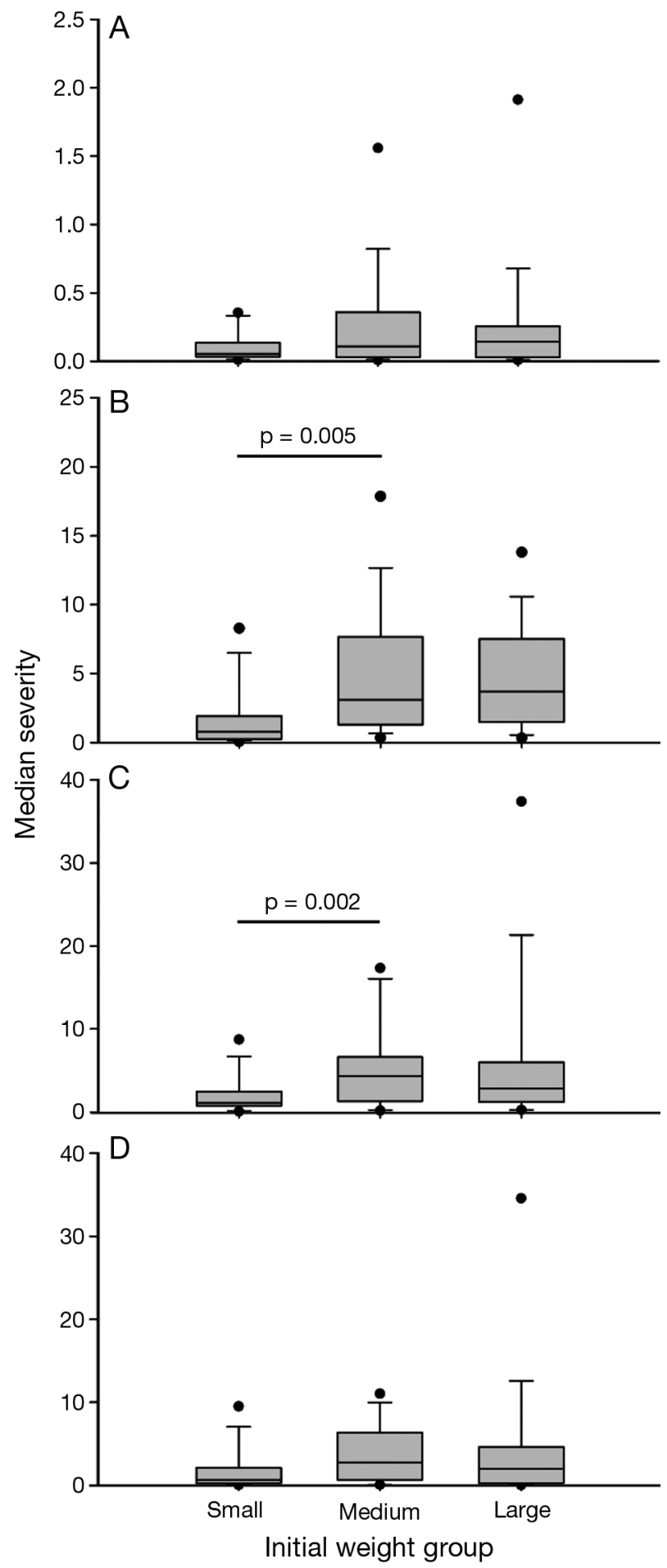

Fig. 2. Trial 2: Initial weight group (IWG)-associated median severity (plasmodia $\mathrm{mm}^{-2}$ ) of Kudoa thyrsites in Atlantic salmon Salmo salar skeletal muscle at (A) 1000, (B) 1500, (C) 2000 and (D) 2500 degree-days following exposure to infectious seawater (note $y$-axis scales differ among plots; see Section 2.1 for IWG definitions). Boxes: median and 25th/ 75th percentiles, whiskers: 10th/90th percentiles, dots: 5th/ 95th percentiles. Significant differences between treatments at a given sampling time are denoted by $\mathrm{p}$-values 
smaller fish. Speculation on possible explanations for this size-associated pattern of infection may be helpful in defining future research. It has been established that the skin, gills and buccal cavity are routes of infection for several myxozoan parasites (Kallert et al. 2007). Additionally, in freshwater teleosts, gill surface area increases allometrically with fish weight (Palzenberger \& Pohla 1992), and the surface area of juvenile Atlantic salmon (exclusive of gills) varies directly with length or weight (Tucker et al. 2002). A significant positive relationship was reported between swimming performance and spore density in $K$. inornata-infected sea trout (McElroy et al. 2015). Those authors rejected the hypothesis that this relationship reflects a tendency for more severe infection in larger fish, although another study reported that prevalence of $K$. inornata increased with fish length (Arnott et al. 2017). In general, nothing is known about the routes of infection by Kudoa spp., and larger fish may be at greater risk of infection simply because more area is available for uptake of the putative infective stage, as suggested earlier for metazoan parasites (Poulin 2000). Alternatively, if the route of $K$. thyrsites infection is via the buccal cavity or gut, similar to that of Henneguya ictaluri, the cause of proliferative gill disease in channel catfish Ictalurus punctatus (Belem \& Pote 2001), a higher rate of infection may occur in larger fish as a result of an elevated feeding rate. The increased occurrence of infection in larger fish may also be related to differential development of skeletal muscle among the IWGs. In both trials in the present study, the salmon were graded from common stocks, and on average, larger IWGs included individuals with higher growth rates. New, smaller muscle fibres are continuously recruited to the skeletal muscle during growth in salmon (Johnston et al. 2000) and a high proportion of these newly recruited fibres is expected to occur in rapidly growing fish (Weatherley et al. 1988). Thus, we predict a higher proportion of newly recruited muscle fibres in fish from the large IWGs; however, nothing is known about the affinity of these fibres for early $K$. thyrsites developmental stages (Young \& Jones 2005, Marshall et al. 2016) or the subsequent proliferative development of the parasite.

It is important to differentiate our observations from the large body of knowledge that describes increasing prevalence or intensity of myxozoan infections with size (or age) in wild or cultured fish (Lom \& Dyková 1992). The positive correlation of Kudoa ciliatae prevalence with body size was suggested to be related to the cumulative effects of prolonged exposure in juvenile Indo-Pacific whiting Sil- lago maculata (Hallett et al. 1997). Similarly, accumulation or proliferation may explain the increased prevalence of Ceratomyxa merlangi and Myxidium gadi with larger size classes in whiting Merlangius merlangus from the Black Sea (Özer et al. 2017). The greater prevalence of Sphaerospora dicentrarchi in larger, older European seabass Dicentrarchus labrax was suggested to have been related either to a cumulative process, or to the greater consumption of or increased proximity to alternative hosts (Castro et al. 2018). Given the limits imposed on the interval of exposure in the present study, accumulation of infection does not explain our findings. Nevertheless, our study indicates the importance of considering host size or intrinsic growth rate, independent of ageassociated accumulation, when attempting to interpret myxozoan infection parameters among age classes of wild or captive fish.

In conclusion and refuting our hypothesis (risk of infection with $K$. thyrsites is increased in smaller post-smolt Atlantic salmon), data from 2 controlled trials revealed a significant host size effect in which the prevalence and severity of $K$. thyrsites were greater in larger Atlantic salmon post-smolts. While our data did not reveal a mechanism for this effect, the generation of treatment groups of distinct size from age-matched salmon suggests a role of growth rate. This research suggests 2 hypotheses to be tested in future research: newly recruited, smaller skeletal muscle fibres are more prone to infection with $K$. thyrsites, and infection severity and host size are statistically interacting factors that affect swimming performance in salmon.

Acknowledgements. This research was funded by Fisheries and Oceans Canada's Aquaculture Collaborative Research and Development Program with support from Marine Harvest Canada and Cermaq Canada. Thanks to Steve Cho, Holly Hicklin and An Yuxin for assistance with fish husbandry and histological processing and microscopy.

\section{LITERATURE CITED}

Arnott SA, Dyková I, Roumillat WA, de Buron I (2017) Pathogenic endoparasites of the spotted seatrout, Cynoscion nebulosus: patterns of infection in estuaries of South Carolina, USA. Parasitol Res 116:1729-1743

Belem AMG, Pote LM (2001) Portals of entry and systematic localization of proliferative gill disease organisms in channel catfish Ictalurus punctatus. Dis Aquat Org 48: $37-42$

Braden LM, Rasmussen KJ, Purcell SL, Ellis L and others (2018) Acquired protective immunity in Atlantic salmon Salmo salar against the myxozoan, Kudoa thyrsites, is associated with induction of $\mathrm{MHII} \beta^{+}, \mathrm{CD} 83^{+}$antigen presenting cells. Infect Immun 86:e00556-17 
Castro R, Cavaleiro FI, Rangel LF, Rocha S, Severino R, Casal G, Santos MJ (2018) Myxozoan parasites of the European sea bass, Dicentrarchus labrax (Teleostei: Moronidae): correlates of infections at the micro- and macroenvironmental scales. Aquaculture 485:17-24

* Dawson-Coates JA, Chase JC, Funk V, Booy MH and others (2003) The relationship between flesh quality and numbers of Kudoa thyrsites plasmodia and spores in farmed Atlantic salmon, Salmo salar L. J Fish Dis 26:451-459

Funk VA, Raap M, Sojonky K, Jones S, Robinson J, Falkenberg K, Miller KM (2007) Development and validation of an RNA- and DNA-based quantitative PCR assay for determination of Kudoa thyrsites infection levels in Atlantic salmon Salmo salar. Dis Aquat Org 75:239-249

Funk VA, Olafson RW, Raap M, Smith D and others (2008) Identification, characterization and deduced amino acid sequence of the dominant protease from Kudoa paniformis and $K$. thyrsites: a unique cytoplasmic cysteine protease. Comp Biochem Physiol B 149:477-489

* Hallett SL, O'Donoghue PJ, Lester RJG (1997) Infections by Kudoa ciliatae (Myxozoa: Myxosporea) in Indo-Pacific whiting Sillago spp. Dis Aquat Org 30:11-16

Harrell LW, Scott TM (1985) Kudoa thyrsitis (Gilchrist) (Myxosporea: Multivalvulida) in Atlantic salmon, Salmo salar L. J Fish Dis 8:329-332

Johnston IA, Alderson R, Sandham C, Mitchell D and others (2000) Patterns of muscle growth in early and late maturing populations of Atlantic salmon Salmo salar L. Aquaculture 189:307-333

Jones SRM, Forster I, Liao X, Ikonomou MG (2012) Dietary nicarbazin reduces severity of Kudoa thyrsites (Myxozoa: Multivalvulida) in Atlantic salmon Salmo salar post smolts. Aquaculture 342-343:1-6

Jones SRM, Cho S, Nguyen J, Mahony A (2016) Acquired resistance to Kudoa thyrsites in Atlantic salmon Salmo salar following recovery from a primary infection with the parasite. Aquaculture 451:457-462

Kabata Z, Whitaker DJ (1981) Two species of Kudoa (Myxosporea: Multivalvulida) parasitic in the flesh of Merluccius productus (Ayres, 1855) (Pisces: Teleostei) in the Canadian Pacific. Can J Zool 59:2085-2091

Kabata Z, Whitaker DJ (1989) Kudoa thyrsites (Gilchrist, 1924) (Myxozoa) in the cardiac muscle of Pacific salmon (Oncorhynchus spp.) and steelhead trout (Salmo gairdneri). Can J Zool 67:341-342

Kabata Z, Whitaker DJ, Bagshaw JW (1986) Kudoa thyrsites (Gilchrist) (Myxosporea: Multivalvulida) in coho salmon Oncorhynchus kisutch (Walbaum). Can J Zool 64: 1038-1040

Kallert DM, Ponader S, Eszterbauer E, El-Matbouli M, Haas W (2007) Myxozoan transmission via actinospores: new insights into mechanisms and adaptations for host invasion. Parasitology 134:1741-1750

King J, McFarlane GA, Jones SRM, Gilmore SR, Abbot CL (2012) Stock delineation of migratory and resident Pacific hake in Canadian waters. Fish Res 114:19-30

Lafferty KD, Harvell CD, Conrad JM, Friedman CS and others (2015) Infectious Diseases Affect Marine Fisheries and Aquaculture Economics. Annu Rev Mar Sci 7: 471-496

Lenth R (2018) emmeans: Estimated Marginal Means, aka Least-Squares Means. https://CRAN.R-project.org/ package $=$ emmeans

Lom J, Dyková I (1992) Protozoan parasites of fishes. Elsevier, Amsterdam

Marshall WL, Sitjà-Bobadilla A, Brown HM, MacWilliam T and others (2016) Long-term epidemiological survey of
Kudoa thyrsites (Myxozoa) in Atlantic salmon (Salmo salar L.) from commercial aquaculture farms. J Fish Dis 39:929-946

*McElroy E, George A, de Buron I (2015) The muscle dwelling myxozoan, Kudoa inornata, enhances swimming performance in the spotted seatrout, Cynoscion nebulosus. Parasitol Res 114:2451-2457

*Morado JF, Sparks A (1986) Observations on the host-parasite relations of the Pacific whiting, Merluccius productus (Ayres), and two myxosporean parasites, Kudoa thyrsites (Gilchrist, 1924) and Kudoa paniformis Kabata and Whitaker, 1981. J Fish Dis 9:445-455

*Moran JDW, Kent ML (1999) Kudoa thyrsites (Myxozoa: Myxosporea) infections in pen-reared Atlantic salmon in the northeast Pacific Ocean with a survey of potential nonsalmonid reservoir hosts. J Aquat Anim Health 11: 101-109

*Moran JDW, Whitaker DJ, Kent ML (1999a) A review of the myxosporean genus Kudoa Meglitsch, 1947, and its impact on the international aquaculture industry and commercial fisheries. Aquaculture 172:163-196

* Moran JDW, Margolis L, Webster JM, Kent ML (1999b) Development of Kudoa thyrsites (Myxozoa: Myxosporea) in netpen-reared Atlantic salmon determined by light microscopy and a polymerase chain reaction test. Dis Aquat Org 37:185-193

长 Özer A, Yurakhno V, Öztük T, Kornyychuk YM (2017) Myxosporean parasites of Ceratomyxa merlangi and Myxidium gadi in whiting Merlangius merlangus: a comparative epizootiological analysis based on samples from two localities off southern and northern coasts of the Black Sea. Parasitol Res 116:2463-2469

* Palzenberger M, Pohla H (1992) Gill surface area of water-breathing freshwater fish. Rev Fish Biol Fish 2: 187-216

Pinheiro J, Bates D, DebRoy S, Sarkar D and R Core Team (2017) nlme: linear and nonlinear mixed effects models. https://CRAN.R-project.org/package=nlme

Poulin R (2000) Variation in the intraspecific relationship between fish length and intensity of parasitic infection: biological and statistical causes. J Fish Biol 56:123-137

R Core Team (2017) R: A language and environment for statistical computing. R Foundation for Statistical Computing, Vienna. https://www.R-project.org/

St-Hilaire S, Hill M, Kent ML, Whitaker DJ, Ribble C (1997) A comparative study of muscle texture and intensity of Kudoa thyrsites infection in farm-reared Atlantic salmon Salmo salar on the Pacific coast of Canada. Dis Aquat Org 31:221-225

* Stehr C, Whitaker DJ (1986) Host-parasite interactions of the myxosporeans Kudoa paniformis Kabata and Whitaker, 1981 and Kudoa thyrsites (Gilchrist, 1924) in the muscle of Pacific whiting Merluccius productus (Ayres): an ultrastructural study. J Fish Dis 9:505-517

* Tucker CS, Sommerville C, Wootten R (2002) Does size really matter? Effects of fish surface area on the settlement and initial survival of Lepeophtheirus salmonis, an ectoparasite of Atlantic salmon Salmo salar. Dis Aquat Org 49:145-152

*Weatherley AH, Gilla HS, Lobo AF (1988) Recruitment and maximal diameter of axial muscle fibres in teleosts and their relationship to somatic growth and ultimate size. J Fish Biol 33:851-859

*Young CA, Jones SRM (2005) Epitopes associated with mature spores not recognized on Kudoa thyrsites from recently infected Atlantic salmon smolts. Dis Aquat Org 63:267-271 